\title{
Practice nurses' workload, career intentions and the impact of professional isolation: A cross-sectional survey
}

\author{
Catherine A O'Donnell*, Hussein Jabareen, Graham CM Watt
}

\begin{abstract}
Background: Practice nurses have a key role within UK general practice, especially since the 2004 GMS contract. This study aimed to describe that role, identify how professionally supported they felt and their career intentions. An additional aim was to explore whether they felt isolated and identify contributory factors.

Methods: A cross-sectional questionnaire survey in one large urban Scottish Health Board, targeted all practice nurses $(n=329)$. Domains included demographics, workload, training and professional support. Following univariate descriptive statistics, associations between categorical variables were tested using the chi-square test or chi-square test for trend; associations between dichotomous variables were tested using Fisher's Exact test. Variables significantly associated with isolation were entered into a binary logistic regression model using backwards elimination.
\end{abstract}

Results: There were 200 responses (61.0\% response rate). Most respondents were aged 40 or over and were practice nurses for a median of 10 years. Commonest clinical activities were coronary heart disease management, cervical cytology, diabetes and the management of chronic obstructive pulmonary disease. Although most had a Personal Development Plan and a recent appraisal, 103 (52.3\%) felt isolated at least sometimes; 30 (15.5\%) intended leaving practice nursing within 5 years.

Isolated nurses worked in practices with smaller list sizes $(p=0.024)$ and nursing teams $(p=0.003)$; were less likely to have someone they could discuss a clinical/professional $(p=0.002)$ or personal $(p<0.001)$ problem with; used their training and qualifications less ( $<<0.001)$; had less productive appraisals $(p<0.001)$; and were less likely to intend staying in practice nursing $(p=0.009)$. Logistic regression analysis showed that nurses working alone or in teams of two were 6-fold and 3.5-fold more likely to feel isolated. Using qualifications and training to the full, having productive appraisals and planning to remain in practice nursing all mitigated against feeling isolated.

Conclusions: A significant proportion of practice nurses reported feeling isolated, at least some of the time. They were more likely to be in small practices and more likely to be considering leaving practice nursing. Factors contributing to their isolation were generally located within the practice environment. Providing support to these nurses within their practice setting may help alleviate the feelings of isolation, and could reduce the number considering leaving practice nursing.

\footnotetext{
* Correspondence: Kate.O'Donnell@clinmed.gla.ac.uk General Practice \& Primary Care, Division of Community-based Sciences, Faculty of Medicine, University of Glasgow, 1 Horselethill Road, Glasgow G12 9LX, UK
} 


\section{Background}

Practice nurses are an integral part of general practice/ family medicine teams in the UK, with a role which encompasses general treatment room duties, nursing duties and chronic disease management [1].

In 2004, a new General Medical Services contract was introduced in the UK. Unlike previous contracts, this is held at practice-level, not with individual general practitioners (family practitioners) [2]. Another key development was the introduction of the Quality and Outcomes Framework (QOF), a pay-for-performance measure covering both clinical and organisational areas of work [3]. Within the clinical domains, there is a focus on chronic diseases with points awarded for care in areas such as coronary heart disease, diabetes and asthma and it is estimated that practices can now earn up to one-third of their income from QOF payments, by meeting these targets [4]. Practice nurses have played a key role in the achievement of QOF points [5-7], as predicted when the contract was implemented $[3,8]$. However, while the evidence suggests that practice nurses are embracing these new roles, there have been negative consequences too. Nurses complain that their workload has increased dramatically, that adherence to "box-ticking" for the QOF impacts on the holistic nature of the nurse-patient consultation and that their remuneration has been less than expected, given the financial gains for practices [5-7].

Practice nurses are employees of the doctors in the practice where they work. While there are advantages to this in terms of the cohesiveness of practice teams, disadvantages include the exclusion of practice nurses from many strategic documents, including Agenda for Change which outlined new terms and conditions of employment for non-medical NHS staff [9], and the lack of nationally recognised terms and conditions for employment [10]. Practice nurses, particularly those working in small practices, may also be more likely to work alone with fewer opportunities for inter-professional contact, reflecting the situation faced by doctors working in small practices. However, while the impact of isolation has been the focus of attention when it affects doctors [11], there has been little or no attention paid to professional isolation as it impacts on practice nurses.

These developments need to be considered in the wider context of nursing recruitment and retention. Recruitment and retention of staff presents challenges for both nursing and medicine, in the UK and abroad [12-16]. While many studies have focussed on secondary care nursing, primary care is faced with similar problems $[17,18]$. Buchan identified that, by 2010 , one in four nurses would be aged 50 or more, with general practice nursing particularly affected [17]. Other factors associated with problems in the recruitment and retention of nurses include job dissatisfaction [12] and perceived work ability, a concept which includes commitment to education and training, employment history, relationships with colleagues and managerial support [16].

In an attempt to explore some of these issues, and to inform the development of later qualitative work exploring nurses' views of their role post-GMS contract, we conducted a questionnaire survey in one large urban Health Board area in Scotland. Conducted late in 2005, we wished to describe the role that practice nurses were undertaking post-GMS contract, to find out how professionally supported they felt in their work and to identify their career intentions. In particular, we used this as an opportunity to explore whether or not nurses felt isolated in their daily role and what factors may contribute to that. This work was conducted in collaboration with the Health Board, who wished to use the findings of the questionnaire to develop support structures for practice nurses and to inform workforce planning.

\section{Methods}

\section{Study design and setting}

The study was a descriptive cross-sectional survey of practice nurses working in general practice within a large, urban Health Board, using a self-completion postal questionnaire. It was conducted in collaboration with the Health Board's Primary Care Division practice nurse advisor and the workforce planning project manager.

\section{Study population and questionnaire distribution}

The target population was all 329 practice nurses working within the Health Board in 2005. The practice nurse advisor distributed the questionnaire on our behalf; completed questionnaires were returned to the research team. The Local Research Ethics Committee requested that no nurse or practice identifier be included on the questionnaire, thus a blanket reminder was sent out 21 days after the initial questionnaire, again through the practice nurse advisor. Completion of the questionnaire was taken to mean the nurses consented to participate in the survey, i.e. implied consent.

\section{Questionnaire design}

Questionnaire items were derived from three sources: a literature review on the role of practice nurses; discussions with nurses in management positions within the Health Board; and a previous questionnaire conducted by the practice nurse advisor in early 2004 . The literature review covered a range of areas, including the development of the practice nurse role in primary care; practice nurse workload; policy drivers contributing to the development of the practice nurse role (for example, Liberating the Talents [19] and Agenda for Change [9]; and literature on skill mix and role development, including work by Sibbald et al on skill mix [20] and Daly and 
Carnwell's work on developing a framework for nursing roles [21]. Items from the previous questionnaire on nursing activities and training were also included.

The final questionnaire covered six domains, with 90 items (see Additional File 1). The domains were personal demographics; practice structure; professional and educational qualifications and career intentions; workload and clinical roles; training and continuing professional development; access to professional support.

Most items were categorical variables, some dichotomous. At the end of the questionnaire respondents were given the opportunity to add any further comments regarding their role and support issues. Before distribution, the questionnaire was shown to colleagues and nurses undertaking the Master in Primary Care within General Practice and Primary Care to assess the ease of completion and validity of the questionnaire.

\section{Data entry and analysis}

Responses were entered into SPSS 11.5 by HJ. A 10\% sample was double entered by a departmental secretary to check for data quality and consistency. No major issues in the accuracy of data entry were detected.

Descriptive univariate analyses were conducted using frequency tables; not all practice nurses provided an answer for every question, so the results are presented as the number and frequency (\%) of responses. Continuous variables were not normally distributed, therefore median and inter-quartile ranges were reported and comparisons analysed by the Mann-Whitney U test. Bivariate analysis was used to further explore the association between isolation and a range of variables. Associations between categorical variables were tested using the chi-square test or, where one variable was ordered, the chi-square test for trend. Fisher's Exact test was used to examine associations between dichotomous variables [22]. Variables that, on bivariate analyses, were significantly associated with isolation $(\mathrm{p}<0.05)$ were entered into a binary logistic regression model using backwards elimination [23].

\section{Ethical approval}

The study was approved by the NHS Greater Glasgow Primary Care Research Ethics Committee (REC Reference Number: 05/S0706/30).

\section{Results}

\section{Demographics and practice characteristics}

A response rate of $61 \%$ was obtained (200/329 nurses). All respondents were female. About half (49.0\%) were aged $40-49$ years; $29.0 \%$ were 50 or more (Table 1 ). The majority were Grade $\mathrm{G}$ nurses and were Registered General Nurses or State Registered Nurses. However, most had multiple qualifications: $80(40.0 \%)$ had 2 qualifications; 54 (27.0\%) had 3 or more. These included district nursing, specialist nurses in general practice and the practice nurse certificate (Table 1).
Table 1 Description of respondents.

\begin{tabular}{|c|c|}
\hline & Number (\%) \\
\hline \multicolumn{2}{|l|}{ Age categories (years) } \\
\hline $20-39$ & $43(21.7)$ \\
\hline $40-49$ & $97(49.0)$ \\
\hline 50 and above & $58(29.3)$ \\
\hline \multicolumn{2}{|l|}{ Grade } \\
\hline$D, E$ or $F$ & $15(7.8)$ \\
\hline G & $142(73.6)$ \\
\hline $\mathrm{H}$ & $36(18.7)$ \\
\hline \multicolumn{2}{|l|}{ Qualifications $^{\mathrm{a}}$} \\
\hline Registered General Nurse/State Registered Nurse & $192(96.0)$ \\
\hline Enrolled Nurse & $19(9.5)$ \\
\hline Undergraduate Nursing Degree & $45(22.5)$ \\
\hline State Certified Midwife/State Midwife & $50(25.0)$ \\
\hline Registered Mental Health Nurse & $7(3.5)$ \\
\hline District Nurse & $20(10.0)$ \\
\hline Health Visitor & $3(1.5)$ \\
\hline Specialist Nurse in General Practice & $40(20.0)$ \\
\hline Practice Nurse Certificate & $24(12.0)$ \\
\hline Masters Degree & $7(3.5)$ \\
\hline \multicolumn{2}{|l|}{ Practice list size } \\
\hline Up to 2000 patients & $17(8.9)$ \\
\hline $2001-4000$ & $49(25.7)$ \\
\hline $4001-6000$ & $53(27.7)$ \\
\hline $6001-8000$ & $27(13.5)$ \\
\hline $8001-10,000$ & $28(14.7)$ \\
\hline Over 10,000 patients & $17(8.9)$ \\
\hline \multicolumn{2}{|l|}{ Number of practice nurses in the team } \\
\hline 1 & $61(30.8)$ \\
\hline 2 & $85(42.9)$ \\
\hline 3 or more & $52(26.3)$ \\
\hline
\end{tabular}

a. Adds to more than 200, as multiple responses were permitted.

Respondents had worked as practice nurses for 0.5 to 24.0 years, median $=10.0$ years (interquartile range (IQR): 5.0 - 15.0 years). The length of service in their present practice ranged from 0.5 to 24.0 years, median $=7.0$ years (IQR: $3.0-12.0$ years).

The majority $(102,53.4 \%)$ worked in practices with between 2000 and 6000 patients, although about onefifth worked in very small ( $<2000$ patients) or very large $(>10,000$ patients) practices (Table 1$)$. Reflecting this, $43.0 \%$ worked with one other nurse, $26.0 \%$ worked with two other nursing colleagues, but $31.0 \%$ worked alone (Table 1). Almost all respondents (192, 98.0\%) worked in clinics with an appointment system with a median of 26 appointment slots per day (IQR: 20.0 - 33.8). The 
median length per appointment was 15.0 minutes (IQR: 10.0 - 15.0 minutes).

\section{Workload and training}

Nurses were asked about their current clinical activities within the practice (Table 2). Amongst those who responded to these questions (approximately half of the total sample), the most common activities were coronary heart disease (CHD) management (92.0\%), cervical cytology (91.7\%), travel immunizations $(89.8 \%)$ and health promotion (87.7\%). The next most common activities involved chronic disease management (stroke (85.1\%), asthma (84.0\%), diabetes $(84.0 \%)$ and chronic obstructive pulmonary disease (COPD) $(80.2 \%))$. The least common activities were childhood immunizations (29.9\%) and assisting with minor surgery (23.6\%). Nurses had received specialist training in all clinical areas, particularly cervical cytology (92.6\%), diabetes (88.4\%), CHD $(86.2 \%)$ and asthma (83.0\%). The areas where least training had been received were men's health $(24.4 \%)$ and assisting with minor surgery (23.0\%). Reflecting this, $64.2 \%$ of respondents wanted more training in men's health; however the biggest request was for more training in treating minor illness (66.9\% of respondents).

Continuing professional development over the previous three years reflected the increasing focus on chronic disease management, with $134(67.0 \%)$ of respondents attending courses on diabetes, 92 (46.0\%) CHD courses and 81 (40.5\%) courses on stroke. 40 nurses $(20.0 \%)$ had attended a nurse prescribing course, although $48(24.0 \%)$ reported regularly prescribing medication; only $10(5.0 \%)$ had attended a nurse practitioner course.

In-house training was common, with 149 (76.4\%) participating in training activities in their practice in the previous 6 months and 126 (63.6\%) participating in shared training sessions with the GPs in their practice in the previous 6 months.

\section{Professional support and career intentions}

$164(86.3 \%)$ respondents had a Personal Development Plan and 173 (87.4\%) had had a formal appraisal within the previous three years. However, only half the respondents felt their appraisal had been productive $(85$, $49.4 \%)$, with 70 (40.7\%) finding it only a little productive and 17 (9.9\%) reporting their appraisal to be unproductive. With regard to other professional support, 181 (91.4\%) reported having someone they could discuss a clinical or professional problem with; 145 (74.0\%) reported having someone they could discuss a personal problem with. When asked about isolation, however, 86 (43.7\%) reported sometimes feeling isolated and 17 (8.6\%) reported always feeling isolated. Finally, 30 nurses $(15.5 \%)$ did not intend to continue working as a practice nurse in the coming 5 years. There was a significant association between age and the intention to leave practice nursing (Chi-square test for trend $=10.631, \mathrm{df}=1$, $\mathrm{p}=0.001)$, with $18(60.0 \%)$ of those intending to leave aged 50 or more, however the other 12 (40.0\%) were under 50 years.

Table 2 Workload and training needs amongst practice nurses (Number answering yes/Total number of respondents (\%)).

\begin{tabular}{lccc}
\hline & $\begin{array}{c}\text { Currently carrying out } \\
\text { activity }\end{array}$ & $\begin{array}{c}\text { Received specialised training in the } \\
\text { past }\end{array}$ & $\begin{array}{c}\text { Would like more specialised } \\
\text { training }\end{array}$ \\
\hline Assisting with minor surgery & $25 / 106(23.6)$ & $34 / 148(23.0)$ & $31 / 110(28.2)$ \\
Childhood immunizations & $32 / 107(29.9)$ & $61 / 154(39.6)$ & $46 / 116(39.7)$ \\
Clinical leadership \& managing other & $36 / 106(34.0)$ & $50 / 156(32.1)$ & $46 / 113(40.7)$ \\
staff & & & \\
Telephone triage & $40 / 109(36.7)$ & $57 / 159(35.8)$ & $64 / 120(53.3)$ \\
Treating minor illness & $43 / 105(41.0)$ & $49 / 156(31.4)$ & $83 / 124(66.9)$ \\
Men's health & $69 / 108(63.9)$ & $40 / 164(24.4)$ & $86 / 134(64.2)$ \\
Treatment room sessions & $70 / 107(65.4)$ & $73 / 162(45.1)$ & $36 / 124(29.0)$ \\
Family planning & $74 / 105(70.5)$ & $133 / 177(75.1)$ & $75 / 132(56.8)$ \\
Breast awareness & $79 / 106(74.5)$ & $123 / 175(70.3)$ & $42 / 125(33.6)$ \\
Screening for new registrations & $79 / 105(75.2)$ & $64 / 173(37.0)$ & $13 / 130(10.0)$ \\
COPD & $81 / 101(80.2)$ & $108 / 178(60.7)$ & $86 / 140(61.4)$ \\
Diabetes & $84 / 100(84.0)$ & $160 / 181(88.4)$ & $47 / 130(36.2)$ \\
Asthma & $84 / 100(84.0)$ & $166 / 186(83.0)$ & $50 / 136(36.8)$ \\
Stroke & $86 / 101(85.1)$ & $144 / 181(79.6)$ & $54 / 134(40.3)$ \\
CHD & $92 / 100(92.0)$ & $162 / 188(86.2)$ & $53 / 139(38.1)$ \\
Health promotion & $93 / 106(87.7)$ & $143 / 183(78.1)$ & $48 / 128(37.5)$ \\
Travel immunizations & $97 / 108(89.9)$ & $147 / 185(79.5)$ & $74 / 140(52.9)$ \\
Cervical cytology & $99 / 108(91.7)$ & $176 / 190(92.6)$ & $25 / 134(18.7)$ \\
\hline
\end{tabular}




\section{Association of isolation with demographic and workload variables}

The factors associated with feeling isolated were examined more fully. Those replying "yes" or "sometimes" to the question of whether they ever felt isolated were grouped together and categorised as "isolated" with the others categorised as "non-isolated".

Those reporting feelings of isolation were more likely to be aged 40-49 and to be G Grade nurses, although these associations were not statistically significant (Table 3 ). Both groups had been practice nurses for a similar length of time (isolated group: median $=10.0$ years (IQR: 4.0 - 15.0 years); non-isolated group: median = 11.0 years (IQR: 7.0 - 15.0 years); Mann-Whitney U test $=3875.5, \mathrm{p}=0.096)$. Isolated nurses worked in smaller practices (Table 3 ). The median practice list size for the isolated group was 5000 patients (IQR: 3000 - 7500); for the non-isolated group the median was 5500 patients (IQR: 4000 - 8500; Mann-Whitney U test $=3510.5$, $\mathrm{p}=$ $0.016)$. Isolated nurses were more likely to work on their own or in smaller teams (Table 3). There was, however, no significant difference in either number of appointments or appointment times between the two groups (data not shown).

There were no significant differences in the qualifications/certificates obtained by both groups (data not shown), but only $64(67.4 \%)$ of isolated nurses felt their training and qualifications were used to the full in their current job compared with $85(92.4 \%)$ of non-isolated nurses (Fisher's Exact test, $\mathrm{p}<0.001$ ).

There was little difference between the clinical activities undertaken by isolated and non-isolated nurses (Figure 1). However, a greater proportion of isolated nurses were involved in almost all of the listed clinical tasks. This difference was statistically significant for treatment room sessions $(75.0 \%$ of isolated vs $54.3 \%$ of non-isolated: Fisher's Exact test, $\mathrm{p}=0.038$ ) and men's health $(72.1 \%$ of isolated vs $52.2 \%$ of non-isolated: Fisher's Exact test, $\mathrm{p}=0.043$ ).

Isolated nurses were more likely to report needing more training (Table 4). This reached statistical significance for family planning, screening for new registrations, COPD, stroke, CHD and health promotion. Slightly fewer isolated nurses had attended recognised CPD courses across a range a clinical areas, but this was not statistically significant (data not shown). Isolated nurses were less likely to participate in within practice training sessions with other colleagues: $71.3 \%$ of isolated nurses vs $82.8 \%$ of non-isolated nurses (Fisher's Exact test, $\mathrm{p}=0.063$ ). Isolated nurses had had slightly fewer study days in the previous year, but this difference was not significant (isolated nurses: median of 4.0 days (IQR: 2.13 - 5.75); non-isolated nurses: median of 5.0 days (IQR: $3.00-9.25$ ); Mann-Whitney $\mathrm{U}$ test $=$ 3103.0, $\mathrm{p}=0.087$.

Table 3 Risk of feeling isolated by demographic and practice characteristics (Number (\%)).

\begin{tabular}{|c|c|c|c|}
\hline & $\begin{array}{l}\text { Isolated nurses } \\
\quad(n=103)\end{array}$ & $\begin{array}{l}\text { Non-isolated nurses } \\
(\mathrm{n}=94)\end{array}$ & p value \\
\hline \multicolumn{4}{|l|}{ Age categories (years) } \\
\hline $20-39$ & $18(17.5)$ & $24(26.1)$ & Chi-square test for trend $=0.176, d f=1, p=0.675$. \\
\hline $40-49$ & $57(55.3)$ & 39 (42.4) & \\
\hline 50 and above & $28(27.2)$ & $29(31.5)$ & \\
\hline \multicolumn{4}{|l|}{ Grade } \\
\hline$D, E$ or $F$ & $7(7.1)$ & $8(8.7)$ & Chi-square test for trend $=2.350, \mathrm{df}=1, \mathrm{p}=0.125$. \\
\hline G & $79(80.6)$ & $61(66.3)$ & \\
\hline $\mathrm{H}$ & $12(12.2)$ & $23(25.0)$ & \\
\hline \multicolumn{4}{|l|}{ Practice list size } \\
\hline Up to 2000 patients & $12(12.1)$ & $5(5.6)$ & Chi-square test for trend $=5.107, d f=1, p=0.024$ \\
\hline $2001-4000$ & $30(30.3)$ & $18(20.2)$ & \\
\hline $4001-6000$ & $24(24.2)$ & $29(32.6)$ & \\
\hline $6001-8000$ & $15(15.2)$ & $12(13.5)$ & \\
\hline $8001-10,000$ & $12(12.1)$ & $14(15.7)$ & \\
\hline Over 10,000 patients & $6(6.1)$ & $11(12.4)$ & \\
\hline \multicolumn{4}{|c|}{ Number of practice nurses in the team } \\
\hline 1 & $40(38.8)$ & $21(22.8)$ & Chi-square test for trend $=8.847, \mathrm{df}=1, \mathrm{p}=0.003$. \\
\hline 2 & $44(42.7)$ & $39(42.4)$ & \\
\hline 3 or more & 19 (18.4) & $32(34.8)$ & \\
\hline
\end{tabular}




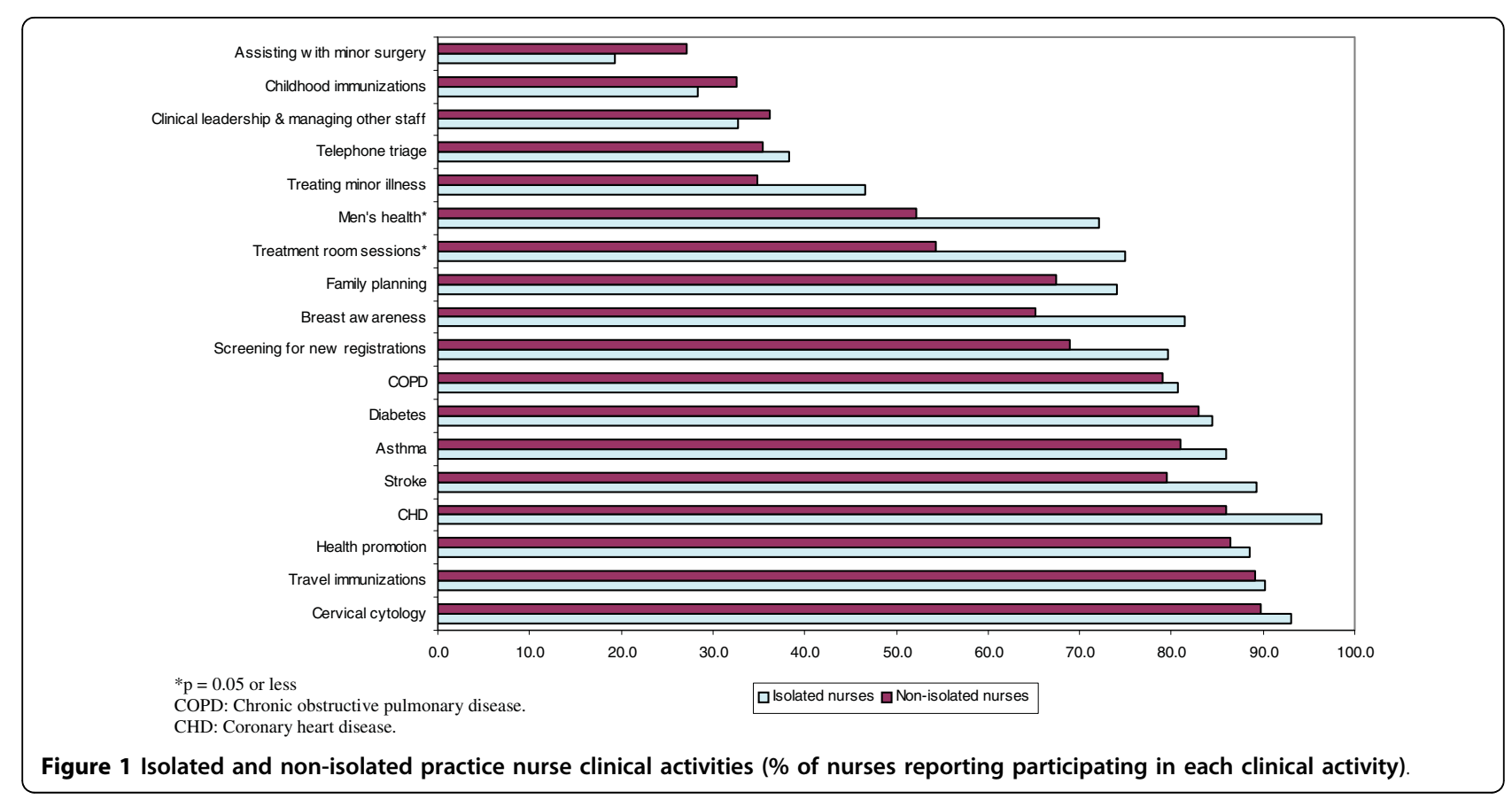

Personal development plans were reported by $82.7 \%$ of isolated nurses and $90.1 \%$ of non-isolated nurses (Fisher's Exact test, $\mathrm{p}=0.146)$. Both groups also reported similar levels of appraisal (84.5\% isolated nurses vs $90.4 \%$ nonisolated nurses; Fisher's Exact test, $\mathrm{p}=0.284$ ). However, isolated nurses were more likely to report that their appraisal was unproductive (66.7\% vs $33.3 \%$ non-isolated nurses, Fisher's Exact test, $\mathrm{p}<0.001)$.
Fewer isolated nurses had access to someone with whom they could discuss a clinical or professional problem $(85.4 \%$ isolated nurses vs $97.9 \%$ non-isolated nurses, Fisher's Exact test, $\mathrm{p}=0.002$ ) or a personal problem $(62.7 \%$ isolated nurses vs $86.0 \%$ non-isolated nurses, Fisher's Exact test, $\mathrm{p}<0.001)$. Only $77.3 \%$ of those who felt isolated planned to continue working as a practice nurse for the coming 5 years compared with

Table 4 Need for future training amongst isolated and non-isolated nurses carrying out the listed clinical activities (Number answering yes/Total number of responders (\%)).

\begin{tabular}{|c|c|c|c|}
\hline & Isolated nurses & Non-isolated nurses & Fisher's Exact test, $p$ value \\
\hline Assisting with minor surgery & $15 / 55(27.3)$ & $15 / 54(27.8)$ & 1.000 \\
\hline Childhood immunizations & $22 / 60(36.7)$ & $23 / 55(41.8)$ & 0.702 \\
\hline Clinical leadership \& managing other staff & $26 / 58(44.8)$ & $19 / 54(35.2)$ & 0.338 \\
\hline Telephone triage & $39 / 64(60.9)$ & $24 / 55(43.6)$ & 0.068 \\
\hline Treating minor illness & $48 / 67(71.6)$ & $34 / 56(60.7)$ & 0.250 \\
\hline Men's health & $50 / 73(68.5)$ & $35 / 60(58.3)$ & 0.277 \\
\hline Treatment room sessions & $23 / 67(34.3)$ & $12 / 56(21.4)$ & 0.160 \\
\hline Family planning & $47 / 71(66.2)$ & $28 / 60(46.7)$ & 0.033 \\
\hline Breast awareness & $25 / 67(37.3)$ & $17 / 57(29.8)$ & 0.448 \\
\hline Screening for new registrations & $11 / 67(16.4)$ & $2 / 62(3.2)$ & 0.017 \\
\hline COPD & $51 / 72(70.8)$ & $34 / 67(50.7)$ & 0.023 \\
\hline Diabetes & $28 / 66(42.4)$ & 19/63 (30.2) & 0.200 \\
\hline Asthma & $31 / 69(44.9)$ & $19 / 66(28.8)$ & 0.074 \\
\hline Stroke & $36 / 71(50.7)$ & $17 / 62(27.4)$ & 0.008 \\
\hline $\mathrm{CHD}$ & $39 / 74(52.7)$ & $13 / 64(20.3)$ & $<0.001$ \\
\hline Health promotion & $32 / 65(49.2)$ & $15 / 62(24.2)$ & 0.006 \\
\hline Travel immunizations & $36 / 72(50.0)$ & $36 / 66(54.5)$ & 0.613 \\
\hline Cervical cytology & 13/70 (18.6) & $12 / 63$ (19.0) & 1.000 \\
\hline
\end{tabular}

a. Adds to more than 200 , as multiple responses were permitted. 
91.4\% of non-isolated nurses (Fisher's Exact test, $\mathrm{p}=0.009)$.

Within the Health Board area, there were opportunities for practice nurses to meet together. Approximately half of all practice nurses were able to attend these meetings. There was, however, no difference in attendance between nurses who felt isolated and those who did not (data not shown).

\section{Predictors of isolation}

The results of the final binary logistic regression model are shown in Table 5. After accounting for the other variables, working alone was a highly significant predictor of isolation with single-handed nurses over 6-times more likely to report feeling isolated. Nurses working in teams of two were 3.5-times more likely to feel isolated. Training and qualifications being used to the full and having a productive appraisal both significantly reduced feelings of isolation, as did the intention to continue working as a practice nurse in the future, but this was not statistically significant.

\section{Discussion}

Nurses working in UK general practice are an important part of the primary care workforce, particularly since the implementation of the new GMS contract $[5,6,8]$. In general, our findings agree with other national surveys conducted over the past 15 years, which showed that most practice nurses were aged 40 and over; most were Grade $\mathrm{G}$ nurses and that their workload covered a range of clinical activities, with immunization, cervical cytology, health promotion and chronic disease management clinics featuring prominently [24-27]. However, none of these surveys identified the feeling of isolation that was found here, nor its strong association with intentions to leave practice nursing. These nurses were older, more likely to be employed as Grade G nurses, worked in smaller practices and were either working alone or with one other nursing colleague. Although there was little difference between isolated and non-isolated nurses with respect to their qualifications, isolated nurses were more likely to feel that their qualifications were not being used to the full in their current job and were less likely to be planning to remain in practice nursing.

Isolated nurses were no busier than non-isolated nurses. Clinically, both groups had similar roles, although a greater proportion of isolated nurses participated in each clinical area - particularly in the provision of treatment room sessions, treating minor illness and men's health. More non-isolated nurses took part in activities related to clinical leadership and staff management and in assisting with minor surgery, suggesting that non-isolated nurses may take on more advanced roles within the practice. Although there may appear to be a contradiction in the findings that isolated nurses felt their skills were not used sufficiently, when they appeared to carrying out similar clinical tasks, there are potential explanations. Isolated nurses may be engaged in a wider range of activities, and so have less chance to develop in-depth knowledge in particular areas which could enhance their job satisfaction and sense of being needed in a team; alternatively, they may be feeling more uncertain in their role, particularly if they are covering many areas that they feel unprepared for. These issues could be explored in future studies.

A productive appraisal also appeared to mediate against feeling isolated. Participation in training activities within the practice and attendance at external practice nurse forum meetings was the same in both groups,

Table 5 Association of nurse and practice characteristics with feeling isolated: Binary logistic regression model.

\begin{tabular}{|c|c|c|}
\hline & Odds ratio $(95 \% \mathrm{Cl})$ & $p$ value \\
\hline \multicolumn{3}{|c|}{ Number of practice nurses in the team (Reference group $=3$ or more) } \\
\hline One & $\begin{array}{c}6.44 \\
(2.13 \text { to } 19.46)\end{array}$ & 0.001 \\
\hline Two & $\begin{array}{c}3.49 \\
(1.29 \text { to } 9.45)\end{array}$ & 0.014 \\
\hline \multicolumn{3}{|c|}{ Training used to full (Reference group $=$ no) } \\
\hline Yes & $\begin{array}{c}0.23 \\
(0.08 \text { to } 0.67)\end{array}$ & 0.007 \\
\hline \multicolumn{3}{|c|}{ Appraisal was productive (Reference group $=$ no) } \\
\hline Yes & $\begin{array}{c}0.19 \\
\text { (0.08 to } 0.43 \text { ) }\end{array}$ & $<0.001$ \\
\hline \multicolumn{3}{|c|}{ Working as a practice nurse in 5 years time (Reference group $=$ no) } \\
\hline Yes & $\begin{array}{c}0.33 \\
\text { (0.10 to } 1.03)\end{array}$ & 0.056 \\
\hline
\end{tabular}


suggesting (perhaps surprisingly) that such activities did not affect nurses' feelings of isolation. One potential explanation for this, however, might be that only around half of the respondents reported being able to attend such meetings in the first place.

Other studies have examined characteristics associated with intending to leave the profession, both in nursing $[12,15,16]$ and general practice [28-30]. While factors such as age and workload were important, a key factor was job satisfaction. In some, this related to satisfaction with the job itself [28], while in others it related to wider factors, including dissatisfaction with promotion and training opportunities [12], changing requirements of the job and perceptions of being valued $[15,16]$. Feeling undervalued has been consistently reported by practice nurses since the advent of the 2004 GMS contract $[5,6]$. While we did not ask practice nurses directly about their level of satisfaction with their job, the finding that isolated nurses worked in smaller teams, felt that they did not use their training and qualifications to the fullest and had unproductive appraisals all point to potentially higher levels of dissatisfaction with their role today.

\section{Strengths and limitations}

The survey targeted the entire population of practice nurses working in the Health Board area at that time. It achieved a response rate of $61 \%$, lower than that obtained by Atkin et al in 1992 [24], and Caldow in 2000 [25], similar to that obtained by The Centre for Innovation in Primary Care in 2000 [26] and much higher than that obtained by the WiPP Snapshot Survey in 2006 [27]. It was also conducted at a time when practice nurses were coming to terms with the new GMS contract.

The lack of a practice nurse or practice identifier (as stipulated by the local ethics committee) meant that we could not gauge the representativeness of the responders in relation to the entire population, particularly in relation to the practice population served. In addition, as practice nurses are employees of UK general practitioners (themselves independent contractors), there is no centrally-held data on the demographics of this population. Responders were broadly similar to the characteristics reported for respondents in other, recent surveys of practice nurses [25-27]. Again, however, these surveys could not report on the characteristics of nonresponders due to the lack of population-level data about this workforce. Based on respondents estimates of their practice list size, we can infer that there were more responses from nurses working in large practices (list size $>6000$ patients: $37 \%$ of respondents' practices versus $26 \%$ of NHS Greater Glasgow's practices) and less from small practices (list size < 6000: 60\% of respondents versus $75 \%$ of actual practices). Given the association between small practices and areas of socioeconomic deprivation [31], this implies that there were fewer responses from nurses working in areas of deprivation. We also had no way of independently verifying the data, particularly in relation to workload and clinical activities.

This survey was conducted in late 2005, a time of great change within UK general practice as teams became used to the requirements of the new contract. Given the findings from more recent qualitative work, it is likely that nurses remain feeling isolated while dealing with an increasing workload associated with QOF. Nonetheless, it would be timely to repeat this work, and extend it to a national level, to clarify the current picture in relation to this important professional group.

The questionnaire used was one developed from that previously used within the health board and developed be reviewing the literature and in consultation with nursing colleagues within the board area. Although questionnaires have been used in other studies, these were not completely suitable either because of their content or their focus on hospital-based nursing [16,25,32,33]. However European studies of nurses' plans to leave hospital-based practice do confirm that issues such as perceived work ability, working conditions and support are important in nurses' views as to whether they wish to stay in nursing [16,32,33].

Finally, within the constraints of a self-completion questionnaire, it was not possibly to fully explore what nurses meant by isolation, nor whether this was a frequent or occasional feeling. Free text comments indicated a number of reasons for isolation, including that of working alone within a practice and lack of opportunities for clinical teaching and supervision. In order to fully explore this issue, further qualitative work is recommended.

\section{Conclusions}

Finding solutions to nurses' reports of isolation is of paramount importance, not only for practice nurses as a profession but also for the future development of general practice. Recognition of the role of practice nurses, nationally agreed terms and conditions and more multiprofessional training initiatives have been suggested $[34,35]$. One explanation may be that nurses who report feeling isolated are also, in themselves, less likely to seek opportunities for training and support. However, our findings show that isolated nurses had similar amounts of study leave as non-isolated nurses and attended similar numbers of external practice support meetings. This suggests that while area-based initiatives are important, many of the solutions lie within general practices themselves. Research shows that job satisfaction, and presumably lack of isolation, is highest in practices with a good 
team climate, irrespective of the number of practice staff $[36,37]$. Therefore, we suggest that primary care organisations target their effort on supporting and building the team environment within general practices, regardless of size or staff composition, and that improving conditions for one group of staff should have a positive effect on all staff.

Additional file 1: Practice nurse survey.

Click here for file

[http://www.biomedcentral.com/content/supplementary/1472-6955-9-2S1.DOC]

\section{Acknowledgements}

We would like to thank all the nurses who completed the questionnaire; Gillian Hallyburton, NHS Greater Glasgow Practice Nurse Manager and Chris Carron, NHS Greater Glasgow Workforce Planning Project Manager for invaluable help in designing the questionnaire and for facilitating access to the practice nurses; Glasgow Local Medical Committee for allowing access to practice nurses; and Michere Beaumont, General Practice and Primary Care for assisting with data entry. HJ was supported by a scholarship from The Palestinian Ministry of Higher Education. The views expressed are those of the authors and not necessarily those of the funders or their employers.

\section{Authors' contributions}

$\mathrm{CO}, \mathrm{HJ}$ and GW designed the study; $\mathrm{HJ}$ conducted the study as part of his $\mathrm{PhD}$ degree and conducted the main analyses, with COD and GW supervising. COD conducted additional analyses and drafted the manuscript; all authors commented on the drafts, saw and approved the final version.

\section{Competing interests}

The authors declare that they have no competing interests.

\section{Received: 14 August 2009}

Accepted: 25 January 2010 Published: 25 January 2010

\section{References}

1. Royal College of General Practitioners. Practice nurses. [No 4]. London, Royal College of General Practitioners. RCGP Information Sheet 2004

2. The NHS Confederation, BMA. New GMS contract 2003. Investing in general practice. London 2003

3. Roland M: Linking physicians' pay to the quality of care - A major experiment in the United Kingdom. New England Journal of Medicine 2004, 351:1448-1454

4. Lester $\mathrm{H}$, Majeed $\mathrm{A}$ : The future of the quality and outcomes framework. BMJ 2008, 337:a3017.

5. McGregor W, Jabareen H, O'Donnell CA, Mercer SW, Watt GCM: Impact of the 2004 GMS contract on practice nurses: a qualitative study. $\mathrm{Br} J \mathrm{Gen}$ Prac 2008, 58:711-719.

6. McDonald R, Harrison S, Checkland K, Campbell SM, Roland M: Impact of financial incentives on clinical autonomy and internal motivation in primary care: ethnographic study. BMJ 2007, 334:1357.

7. Grant S, Huby G, Watkins F, Checkland K, McDonald R, Davies H, Guthrie B: The impact of pay-for-performance on professional boundaries in UK general practice: an ethnographic study. Sociology of Health \& IIIness 2009, 31:229-245.

8. Leese B: New opportunities for nurses and other healthcare professionals? A review of the potential impact of the new GMS contract on the primary care workforce. Journal of Health Organization and Management 2007, 20:525-536.

9. Department of Health: Agenda for Change. Final agreement. Leeds, Department of Health 2004.

10. Martin J, Young L: Practice nurses' terms and conditions: A survey. Practice Nursing 2006, 17:570-572.

11. Royal College of General Practitioners: Safeguarding patients: Lessons from the past - proposals for the future. The Fifth Report of the
Shipman Inquiry Chaired by Dame Janet Smith (September 2004). RCGP Summary Paper 2004/08. London, Royal College of General Practitioners 2004.

12. Shields MA, Ward M: Improving nurse retention in the National Health Service in England: the impact of job satisfaction on intentions to quit. Journal of Health Economics 2001, 20:677-701.

13. O'Neil E, Seago JA: Meeting the challenge of nursing and the nation's health. JAMA 2002, 288:2040-2041.

14. Berliner HS, Ginzberg E: Why this hospital nursing shortage is different. JAMA 2002, 288:2742-2744.

15. Finlayson B, Dixon J, Meadows S, Blair G: Mind the gap: the extent of the NHS nursing shortage. BMJ 2002, 325:538-541.

16. Camerino D, Conway PM, Heijden Van der BIJM, Estryn-Behar M, Consonni D, Gould D, Hasselhorn H-M: Low-perceived work ability, ageing and intention to leave nursing: a comparison among 10 European countries. J Adv Nursing 2006, 56:542-552.

17. Buchan J: The 'greying' of the United Kingdom nursing workforce: implications for employment policy and practice. J Adv Nursing 1999, 30:818-826.

18. Audit Commission: A focus on general practice in England. London, Audit Commission 2002

19. Department of Health: Liberating the talents. Helping Primary Care Trusts and nurses to deliver The NHS Plan. London, Department of Health 2002.

20. Sibbald B, Shen J, McBride A: Changing the skill-mix of the health care workforce. Journal of Health Services \& Research Policy 2004, 9:28-38.

21. Daly WM, Carnwell R: Nursing roles and levels of practice: a framework for differentiating between elementary, specialist and advancing nursing practice. Journal of Clinical Nursing 2003, 12:158-167.

22. Altman DG: Practical statistics for medical research London: Chapman \& Hall 1991.

23. Field A: Discovering statistics using SPSS London: SAGE Publications, 22005

24. Atkin K, Lunt N, Parker G, Hirst M: The role and self-perceived training needs of nurses employed in general practice: observations from a national census of practice nurses in England and Wales. J Adv Nursing 1994, 20:46-52.

25. Caldow $\mathrm{L}$, Bond $\mathrm{CM}$, Russell EM: Independent nursing practice: a national survey of attitudes of practice employed nurses in Scotland. Health Bulletin 2001, 59:21-28.

26. The Centre for Innovation in Primary Care: . What do practice nurses do? A study of roles, responsibilities and patterns of work. Sheffield, The Centre for Innovation in Primary Care 2000.

27. Crossman S: The WiPP "SNAPshot survey". Supporting nurses and practice: A national survey investigating employment conditions and professional development support for nurses in general practice in the UK. Working in Partnerhip Programme; Department of Health 2008.

28. Sibbald B, Bojke C, Gravelle $H$ : National survey of job satisfaction and retirement intentions among general practitioners in England. BMJ 2003, 326:22.

29. Sibbald B, Young R: The general practitioner workforce 2000. Workload, job satisfaction, recruitment and retention. Manchester, National Primary Care Research \& Development Centre 2001.

30. Leese B, Young R: Disappearing GPs. Is there a crisis in recruitment and retention of general practitioners in England?. Manchester, National Primary Care Research and Development Centre 1999.

31. Mackay D, Sutton M, Watt G: Deprivation and volunteering by general practices: cross sectional analysis of a national primary care system. BMJ 2005, 331:1449-1451.

32. Stordeur S, D'Hoore W, NEXT-Study Group: Organizational configuration of hospitals succeeding in attracting and retaining nurses. J Adv Nursing 2007, 57:45-58

33. Camerino D, Conway PM, Heijden Van der BIJM, Estryn-Behar M, Costa G, Hasselhorn H-M: Age-dependent relationships between work ability, thinking of quitting the job, and actual leaving among Italian nurses: a longitudinal study. International Journal of Nursing Studies 2008, 45:1645-1659.

34. Swanwick T: The training of general practice nurses: opportunities for collaborative working. Education for Primary Care 2005, 16:56-534.

35. Crossman S: Practice nurses' needs for education since the advent of the new GMS. Practice Nursing 2006, 17:87-91

36. Proudfoot J, Jayasinghe UW, Holton C, Grimm J, Bubner T, Amoroso C, Beilby J, Harris MF, PracCap Research Team: Team climate for innovation: 
what difference does it make in general practice?. Int J Qual Health Care 2007, 1-6.

37. Harris MF, Proudfoot JG, Jaysinghe UW, Holton CH, Powell Davies GP, Amoroso CL, Bubner TK, Beilby JJ: Job satisfaction of staff and the team environment in Australian general practice. Medical Journal of Australia 2007, 186:570-573.

\section{Pre-publication history}

The pre-publication history for this paper can be accessed here:http://www. biomedcentral.com/1472-6955/9/2/prepub

doi:10.1186/1472-6955-9-2

Cite this article as: O'Donnell et al.: Practice nurses' workload, career intentions and the impact of professional isolation: A cross-sectional survey. BMC Nursing 2010 9:2.

Publish with Biomed Central and every scientist can read your work free of charge

"BioMed Central will be the most significant development for disseminating the results of biomedical research in our lifetime. "

Sir Paul Nurse, Cancer Research UK

Your research papers will be:

- available free of charge to the entire biomedical community

- peer reviewed and published immediately upon acceptance

- cited in PubMed and archived on PubMed Central

- yours - you keep the copyright 